\title{
Study of the mechanical properties of Iron-Epoxy composite materials
}

\author{
Abdulhadi K.Judran \\ Department of Laser and Optoelectronic Engineering, University of Technlogy, Baghdad, Iraq \\ E-mail: abdulhadikadhim@yahoo.com
}

\begin{abstract}
Iron-Epoxy composite samples were prepared by added different weight percentages $(0,5,10,15$, and $20 \mathrm{wt} \%)$ from Iron particles in the range of $(30-40 \mu \mathrm{m})$ as a particle size. The contents were mixed carefully, and placed a circular dies with a diameter of $2.5 \mathrm{~cm}$. Different mechanical tests (Shore D Hardness, Tensile strength, and Impact strength ) were carried out for all samples. The samples were immersed in water for ten weeks, and after two weeks the samples were take-out and drying to conducting all mechanical tests were repeated for all samples. The hardness values increased when the Iron particle concentration increased while the Impact strength is not affected by the increasing of Iron particles concentration. The tensile strength results reveal that the tensile strength and the strain values of composite samples decreases when the Iron particles concentration increase. After conducted immersion processes the results of hardness are reduced wears the results of tensile strength and the impact strength are increased.
\end{abstract}

\section{Key words}

Mechanical properties, epoxy, iron particles and composite.

\section{Article info.}

Received: Oct. 2014

Accepted: Jan. 2015

Published: Apr. 2015

$$
\begin{aligned}
& \text { دراسة الخصائص الميكانيكية لمتراكب ايبوكسي - حديد } \\
& \text { عبد الهادي كاظم جدران } \\
& \text { قسم هندسة الليزر و الأكترونيات البصرية، الجامعة التكنولوجية، بغداد، العراق }
\end{aligned}
$$

نماذج المتر اكب تم تحضير ها بأضافة نسب وزنية مختلفة (20 wt \% , 15, 10, 5, 0 (20) من دقائق الحديد وبمعدل حجم

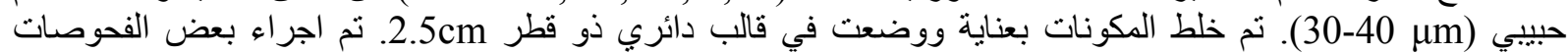

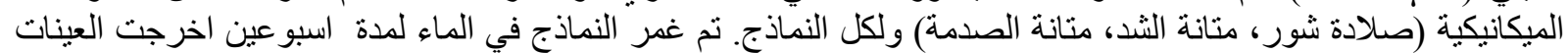

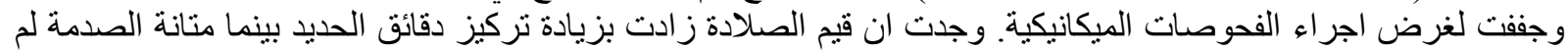

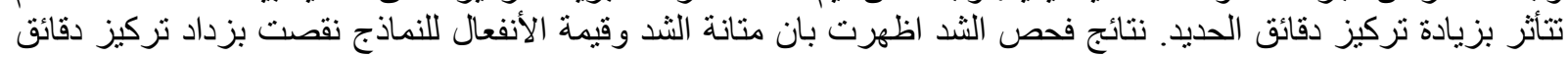

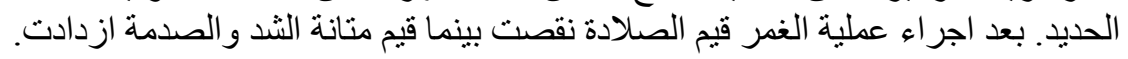

\section{Introduction}

Polymeric composite materials are of versatile scientific and technological significance due to their enhanced mechanical properties, and Epoxy resin as a part of polymeric materials is widely used as an electrical insulation material [1]. However it is fracture behavior is brittle compared with metals, therefore it is necessary to improve the mechanical properties of epoxy resin by adding other materials. Low cost particulate fillers are added to epoxy in commercial production primarily for reasons of economy and improvement in molding characteristics [2-4]. Metal particles added to polymeric 
materials lead to composite with higher density, improved electrical and thermal conductivity, and are therefore of particle interest for specific applications [5]. In 2001 Deya study the effect of Nitric acid, Hydrochloric acid, and UV radiation on mechanical properties of epoxy - fiber glass composite samples and in other time on epoxy-alumina composite and it is found that the effect of solutions acids is bigger than that effect of UV-radiation [6]. Firas was study the effect of environmental on fracture mechanism by impact on epoxyfiber glass and epoxy - metallic wires [7].

The composite means two or more from different materials participation sharing subscription association together fractions volume or weight percentages to produce new material of better properties, and in general the composites are classified into three kinds as follows $[8,9]$ :

I- Fiber composite: In this type the reinforced material is fibers include matrix material.

II- laminated composite: contains two or more layers from different materials are engagements together.

III- Particulate composite: the reinforced material is a metallic or nonmetallic particle dispersed in matrix material as shown in the present work. The properties of any composite can be limited by three points; matrix Material, Reinforcement Material, and Interface of Bonding.

\section{Experimental part}

Composite Iron / Epoxy resin preparation

Epoxy Resin used in this research was quick mast 105 which is involved two materials or two components; base epoxy in the form of liquid and hardener was added the transform to solid state of in a percentage of $3: 1$. Iron particles of average grain size of $30 \mu \mathrm{m}$ and was added to Epoxy in a weight percentages of $0,5,10,15$, and
20 wt $\%$ and mixed carefully in a circular dies to make the composite samples.

\section{Hardness testing}

Shore D Hardness product of Time Group inc. company was used to conduct the Hardness measurement by using dibbing tool. The pointed dibbing tool penetrates in to the sample surface by the pressure applied on the instrument.

\section{Impact testing}

Impact test product of Amityville inc. company was used a chivied impact test for all samples by using fixed lever on the gauge.

The potential energy by a swinging movement will be convert to kinetic energy, and will be lose a part of this energy in breaking of sample; then gauge will be read breaking energy of sample, and the Impact strength was calculated by employing the following equation $[10,11]$.

Impact strength $=\frac{\text { Broken energy }(\mathrm{KD})}{\text { Area of } \operatorname{cross} \operatorname{section}\left(\mathrm{m}^{2}\right)}$

The quantity usually measured is the energy absorbed in breaking of specimen in a single blow.

\section{Tensile strength}

Tensile strength is indicated by the making of a stress -strain Curve and in general indicate when necking will occur. As it an intensive property, the value does not depend on the size of the test specimen. It is however dependent on the preparation of the specimen and the temperature of the test environment and material [12].

\section{Results and discussion \\ Hardness results}

Fig. 1 represents the shore D hardness values as a function of Iron particle concentration in composite samples before 
and after immersion in water for two weeks. From Fig. 1 can be seen that the shore D hardness values increased with the increasing of Iron concentration, this result may be related to the iron particle will be entire the cavities between epoxy resin particle, and then reduce these cavities and this behavior leads to increase the resistance samples to indentation. After immersion all samples in water for two weeks the values of shore D hardness still fixed for pure sample where hardness values reduced for other samples because of the water will be entire in to composite samples close to Iron particle zone and then separate between iron particle and epoxy resin.

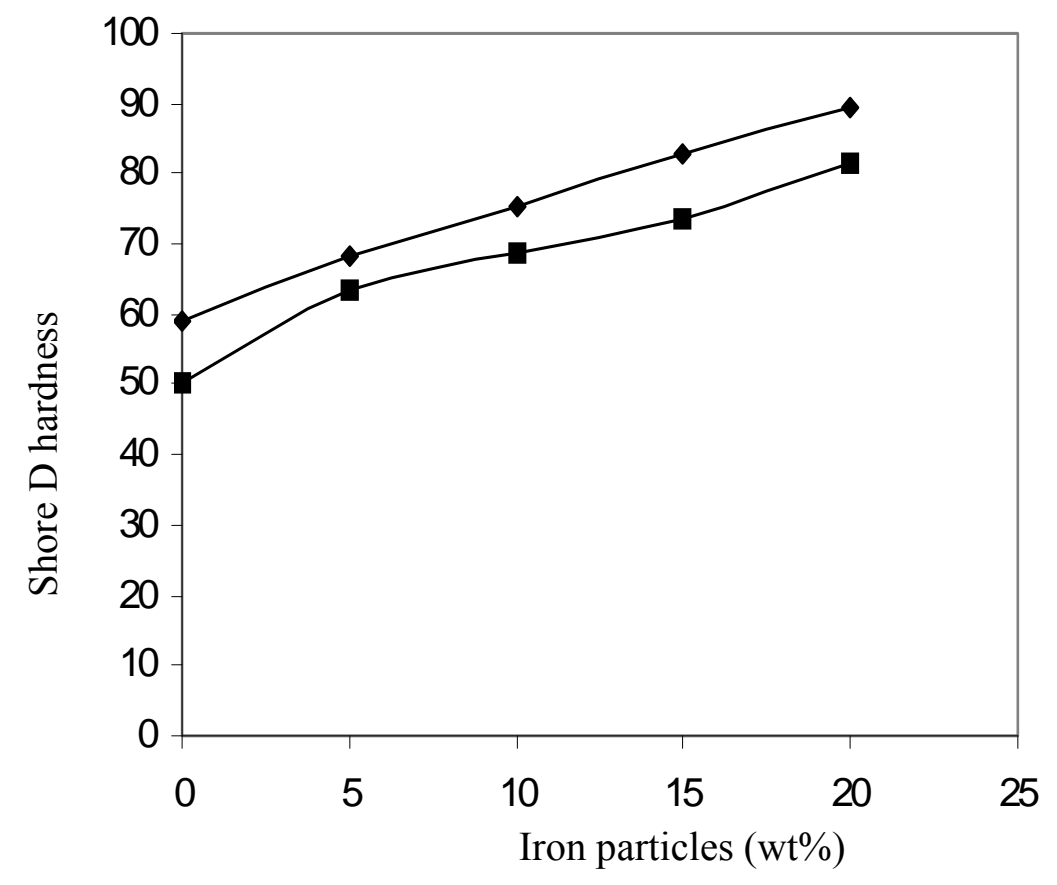

Fig. 1: Shore D Hardness values as a function of Iron particles.

\section{Impact strength Results}

Impact test was done by using Charpy method to evaluate the impact strength. Fig. 2 reveals that the impact strength values for all samples before and after immersion in water are decreased when the Iron particle concentration increased because of that the ability of epoxy resin to absorb the impact energy is greater than composite samples (epoxy/Iron), this conclude related to the Iron particle will be resists the impact energy and the ability to absorb this energy is less than that of pure samples. After immersion all samples in water for two weeks the values of impact strength are increased for all samples (pure epoxy and epoxy/Iron composite samples) with increasing of Iron particle concentration, the reason of this behavior related to that the water will be entire the specimens and become more flexible and the ability to absorb the impact energy will be improved. 


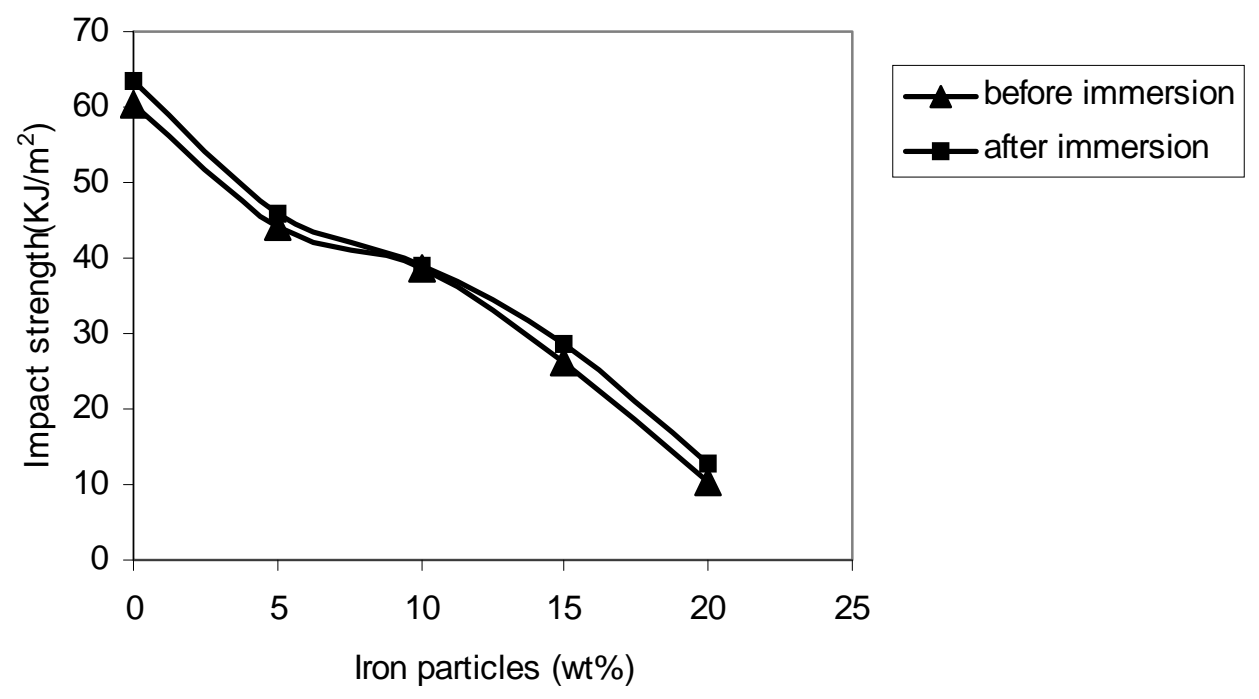

Fig. 2: Impact strength $\left(\mathrm{KJ} / \mathrm{m}^{2}\right)$ values as a function of Iron particles (wt\%).

\section{Tensile strength results}

Fig. 3 shows the tensile strength values as a capacity of Iron particles fixation in composite specimens previously, then after the fact inundation in water for two weeks. From this figure one can be demonstrated that rigidity qualities expanded with the expanding of Iron focus up to $10 \mathrm{wt} \%$ of
Iron particles, this result may be identified with the iron particles will be decreased the yield purpose of composite examples, while Fig. 4 shows the strain as a capacity of Iron particles fixation, and can be demonstrated the strain qualities are diminished when the iron particles fixation expanded up to $10 \mathrm{wt} \%$.

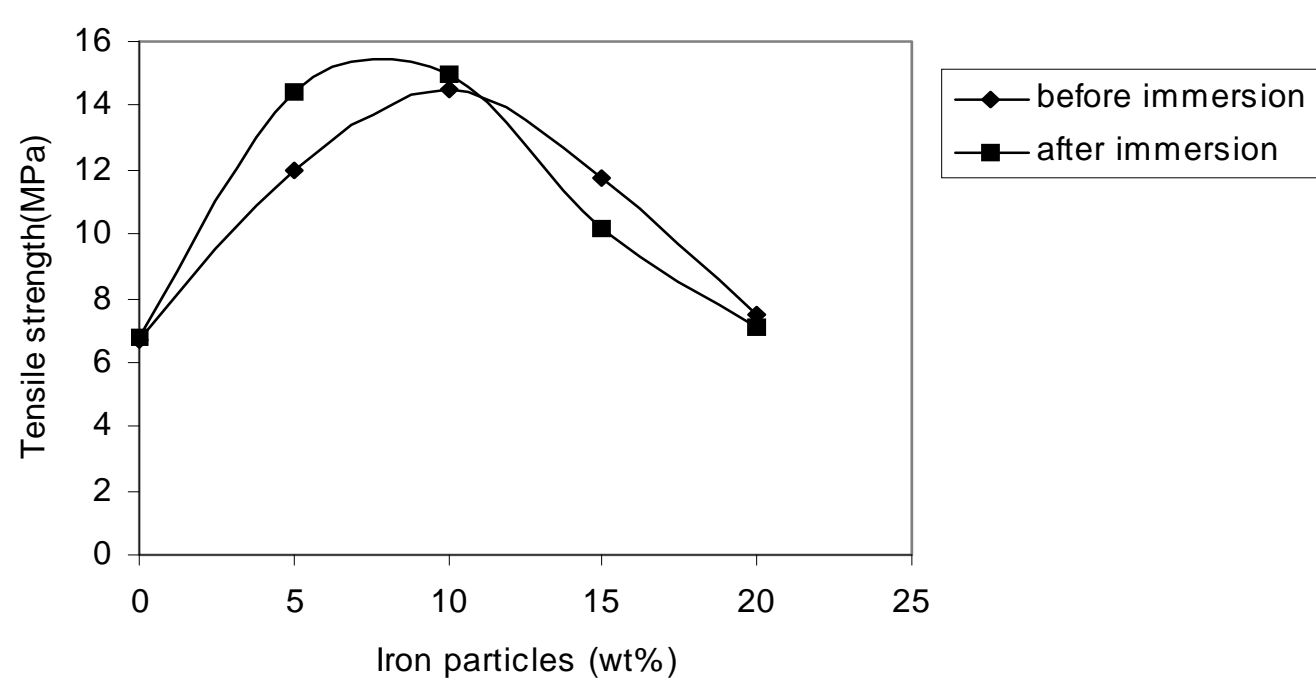

Fig. 3: Tensile strength (MPa) as a function Iron particles (wt\%). 


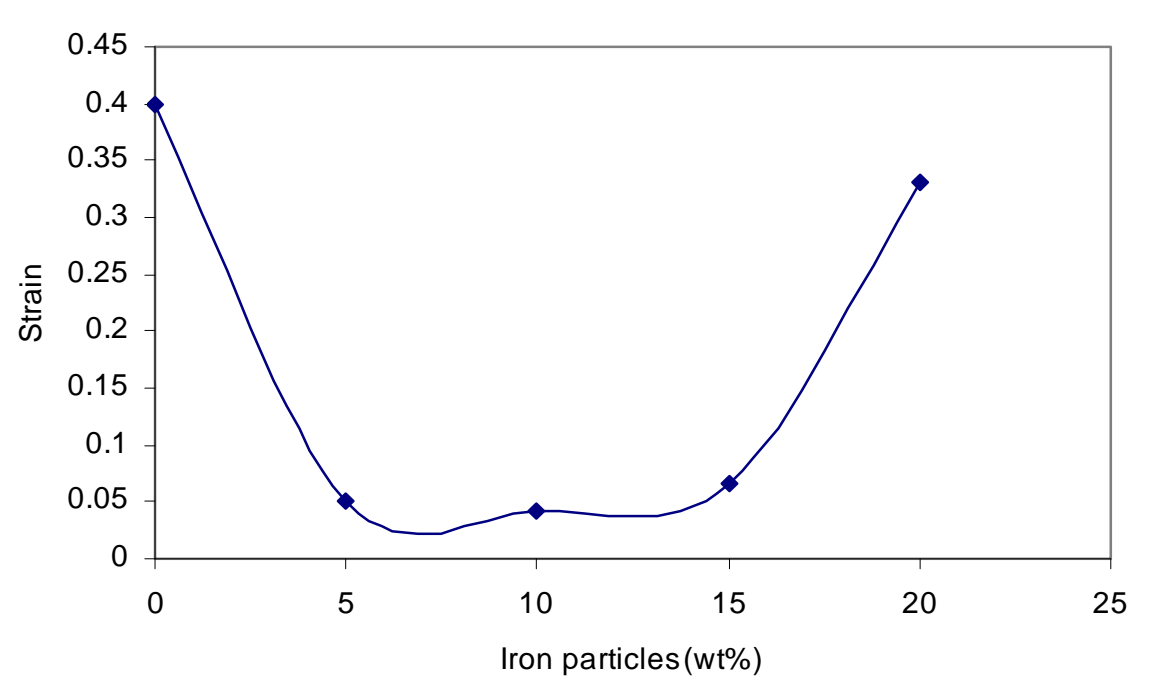

Fig. 4: Composite samples strain (4L/L) as a function of Iron particles (wt\%).

\section{Immersion results}

The results of all mechanical tests after different periods $(2,4,6,8$, and 10) weeks of immersion in water for all specimens are tabulated in Table 1. From this table can be noticed the shore D hardness values are decreased when the immersion in water periods are increased. The impact tests values revealed that the impact strength increased with the increasing of immersion in water periods The tensile strength values increased when the immersion in water periods are increased.

\section{Conclusions}

The main remarks of conclusion can be summarized as follows:

- The shore hardness values of epoxy / Iron particles composite increased when the Iron particles percentages increased.
- The impact strength values of epoxy / Iron particles composite are proportional inversely with the concentration of Iron particles in composite samples.

- The tensile strength of epoxy / Iron particles composite reveals maximum value at the concentration of $10 \mathrm{wt} \%$ for Iron particles in composite samples.

- The maximum strain appear in pure epoxy sample wears the minimum strain values appears in the composite samples of the Iron particles concentration in the range of 5-14wt $\%$.

- The immersion in water reduced the values of shore hardness and the tensile strength wears the values of impact strength are increased after immersion for all epoxy / Iron particles composite. 
Table 1: Mechanical tests values of composite samples in different immersion periods

\begin{tabular}{|c|c|c|c|c|}
\hline $\begin{array}{c}\text { Iron particles } \\
(\mathrm{wt} \%)\end{array}$ & immersion periods (weeks) & Hardness & Impact strength $\left(\mathrm{KJ} / \mathrm{m}^{2}\right)$ & $\begin{array}{c}\text { Tensile strength } \\
(\mathrm{MPa})\end{array}$ \\
\hline 0 & 2 & 58.3 & 63.6 & 6.69 \\
& 4 & 47.2 & 65.2 & 6.72 \\
& 6 & 40.1 & 65.3 & 7.10 \\
& 8 & 52.1 & 64.4 & 7.23 \\
& 10 & 28.0 & 61.4 & 7.42 \\
\hline 5 & 2 & 63.4 & 45.8 & 12.33 \\
& 4 & 61.5 & 46.1 & 12.18 \\
& 6 & 53.9 & 45.6 & 12.45 \\
& 8 & 47.7 & 44.8 & 12.53 \\
\hline 10 & 10 & 35.2 & 43.2 & 14.5 \\
& 2 & 68.52 & 39.12 & 14.40 \\
& 4 & 66.12 & 37.8 & 14.13 \\
& 6 & 60.90 & 36.5 & 13.54 \\
& 8 & 53.7 & 38.7 & 13.00 \\
\hline 15 & 10 & 40.2 & 35.9 & 11.72 \\
& 2 & 73.6 & 28.5 & 11.86 \\
& 4 & 70.7 & 29.6 & 11.46 \\
& 6 & 61.5 & 30.1 & 10.74 \\
& 8 & 54.1 & 28.2 & 9.96 \\
\hline 20 & 10 & 43.7 & 27.5 & 7.5 \\
& 2 & 81.4 & 12.6 & 7.54 \\
& 4 & 70.5 & 10.9 & 7.25 \\
& 6 & 68.3 & 11.3 & 6.87 \\
& 10 & 60.4 & 12.4 & 6.49 \\
\hline
\end{tabular}

\section{References}

[1] A. Allaoui, S. Bai, H. M. Cheng, J. B. Bai, Quick Seaith Science and Technology, 62, 15, Nov. (2002) 1993-1998. [2] V. K. Srivatava, P. S. Shembekar, J. Mater. Sci. 25 (1990) 3513-6

[3] R.P.Ydav, P.C.Gope, P.L.Sah, Proceeding of the $13^{\text {th }}$ international conference on experimental mechanics, Alexandroupolis, Greece , July 1-6, 2007.

[4] V. I. Pokhmurs'kyi V. K. Piddubnyi I. M. Zin' B. M. Lavryshyn L. M. Bilyi M. P. Voloshyn, J. Material Science, 41, 4 (2005) 495-500

[5] L. Nicodemo, L. Nicolais, J. Material Science Letters, 2 (1983) 201-203.
[6] B.M. Deya , Al -Mustansiriya Journal of Science, 12, 3 (2001) 158-163.

[7] F.F. Aluubadai g M.Sc. thesis, University of Technology, 2002.

[8] M.Gryson, John Wiely and Sons, Inc, U.S.A. (1983).

[9] W. Mahdi Hameed Al-Askare, M.Sc. Thesis, Department of Applied Sciences, University of Technology, 2006.

[10] B.H. Al-Shaqbn, M.Sc. Thesis, Department of Applied Sciences University of Technology, 2007.

[11] A. Meyers, Dynamic behavior of materials, Wiley, 1994.

[12] E.J. Pavlina, C.J Van Tyne , J. of Materials Engineering and Performance", 17, 6 (2008) 888-893. 